\title{
System of forming control signals by correction devices with creation of neural network patterns based on matrix analysis
}

\author{
A. V. Manin, D. B. Vayner \\ Federal State-Financed Educational Institution of Higher Education P. A. Solovyo, Rybinsk State \\ Aviation Technical University, Rybinsk, Russia
}

\begin{abstract}
The compensating devices are controlled in the structure of the automatic control system in conjunction with the sensors included in a particular node of the power grid. But the overall state of the local power grid for the reactive power flow is not considered. It is proposed to generate control signals to correction devices by processing the information obtained by monitoring from remote sensors of voltage and current of the distribution grid. It is possible to use the matrix method of forming the control signals to correction devices to adjust the grid parameters. To improve the energy efficiency of correction devices in the monitoring structure, it is proposed to use static reactive power compensators (SVCs) based on magneto-valve elements. The proposed distribution grid monitoring structure with the transfer of information over a local area network from sensors to correction devices makes it possible to stabilize the required grid parameters among consumers and minimize the loss of electrical energy from reactive power flow.
\end{abstract}

\section{Introduction}

Currently, leading scientific research centers associated with the design of power grids, are focused on the new Smart Grid concept [1]. One of the subsystems of the Smart Grid is a flexible alternating current transmission system (FACTS), containing sets of adaptable power components that serve for increasing grid transmission capacity and improving the high-performance of the power grid and consumer reliability improvement [2]. The FACTS is based on reactive power compensation devices and correction devices of various circuitry solutions, e.g. SVCs, with the ability to quickly change the reactive power [3].

As a rule, to control an SVC included in a grid node, an autonomous control system is used [4], which may not take into account the state in more distant nodes of the distributed grid. For a more correct effect on the grid to maintain the required voltage or power factor, the SVC must be connected to a specific grid design node, and must be controlled by a control signal that evaluates the state of the monitored grid. For this purpose, the SVC control system is included in the monitoring of the state of the grid, as a result of which an adjusted control action is generated on the SVC control unit making the effect on the grid parameters more optimal. 


\section{Methods}

The block diagram of the monitoring system of the FACTS objects using a local area network, developed by the authors, is shown in Fig. 1.

The following is the algorithm of the monitoring system according to the proposed structural scheme. Information about the state of the grid parameters comes from the current and a voltage sensor located in the nodes of the distribution grid and is transmitted to the monitoring unit and the controller of data processing via the data transmission module via the local area network. The grid status parameters are compared with the values set by the operator or manager, and as a result, control signals are generated on the corresponding execution units: the SVC, a balancing device, blocks of cosine capacitors, etc. [5]. The control data, likewise, is transmitted via the local area network to the control units of the executive devices.

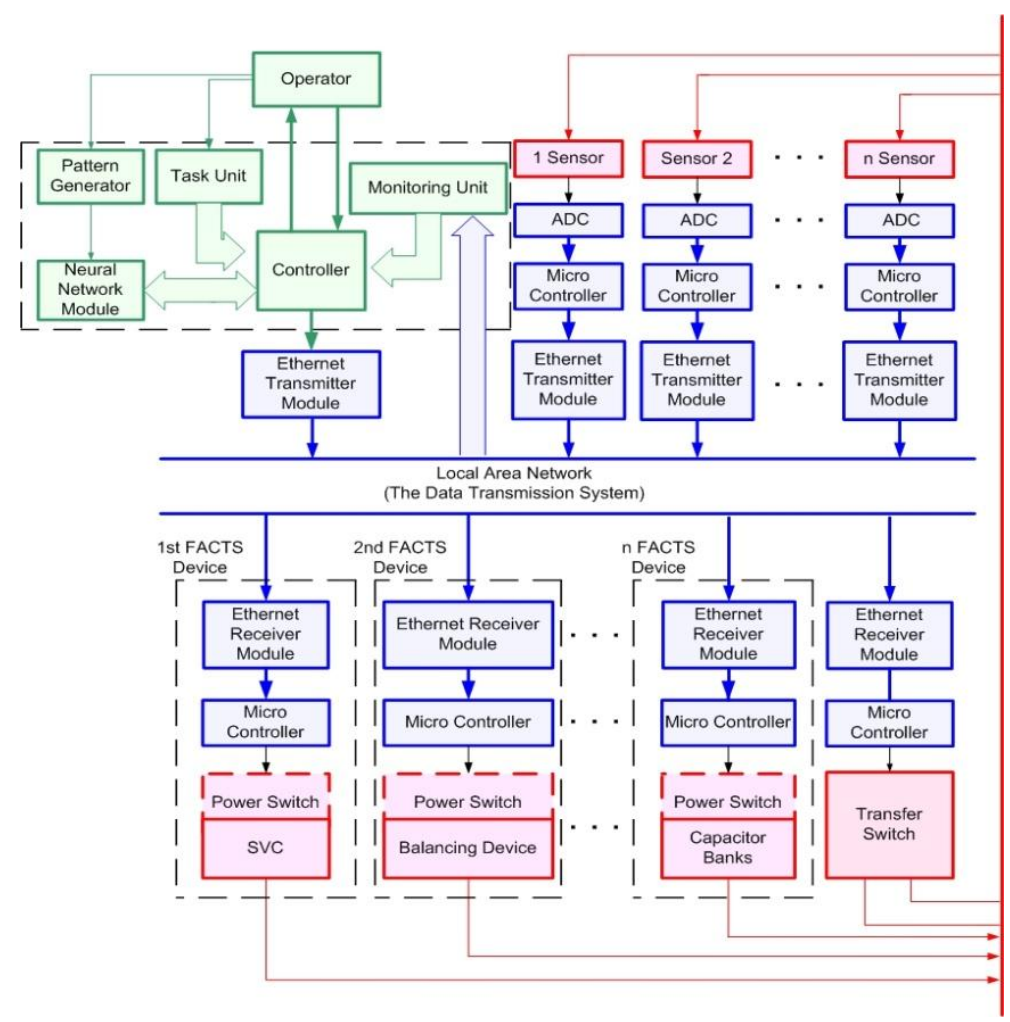

Fig. 1. Block diagram of the monitoring system of FACTS objects using a local area network (developed by the authors).

Additionally, a module with a pattern generator of consumer and emergency modes based on a neural network is included in the controller, information from which correlates control signals, as well as generates control signals for emergency shutdown of network sections or automatic switching on of a backup power source [6]. Particularly interesting is the module for processing parameters of the electrical grid, which contains a model of the considered electrical grid with parameters of supply lines, power sources, and consumer characteristics. Such model can be described by well-known topological methods and it displays electromagnetic processes in the grid under various situations in the power supply 
system: power discharges and surges of consumers, both active and reactive, emergency processes, levels of higher harmonics in the presence of consumers with non-linear currentvoltage characteristics. The model works out possible situations in the electrical grid, writing them into the buffer for translation into the neural network module.

The most interesting thing about the proposed solution to the monitoring problem is the processing of information about the distribution grid parameters in the grid parameter processing module to correct the formation of control signals for execution devices. The analysis of energy processes in an electrical grid by the classical method, based on the compilation and solution of the Kirchhoff system of equations, is a fairly complex and time-consuming process that requires a lot of attention and certain experience [7].

The authors propose to use the method of combined matrices [8]. The concept of this method is to replace the investigated electrical grid with an electromagnetic circuit, which is understood as a combination of electrical and magnetic circuits connected by a winding system. Processes in such circuit are described by a system of equations for complex variables

$$
\begin{aligned}
& E_{K}=Z_{K}^{E} I_{K}+Z_{K}^{E M} F_{K} \\
& 0=Z_{K}^{M E} I_{K}+Z_{K}^{M} F_{K}
\end{aligned}
$$

where $Z_{K}^{E}, Z_{K}^{M}, Z_{K}^{E M}, Z_{K}^{M E}$ - are matrices of circuit resistances of an electrical circuit, magnetic circuit, electromagnetic and magnetoelectric coupling, $E_{K}, I_{K}$ are the matrices of electromotive force (emf) and circuit currents.

The solution for this system of equations is the loop current matrix:

$$
I_{K}=\left[Z_{K}^{E}-Z_{K}^{E M}\left(Z_{K}^{M}\right)^{-1} Z_{K}^{M E}\right]^{-1} E_{K}
$$

which for the case of analysis of electrical grid without electric transformer blocks takes the following form:

$$
I_{K}=\left(Z_{K}^{E}\right)^{-1} E_{K}
$$

Matrices of contour resistances, emf, and currents are associated with branch resistance matrices $Z_{K}^{E}$, branch emf $E_{B}$ and currents $I_{B}$, by relations

$$
E_{K}=G_{E E} E_{B} ; \quad I_{B}=G_{E E}^{T} I_{K} ; Z_{K}^{E}=G_{E E} Z_{B}^{E} G_{E E}^{T},
$$

where $G_{E E}$ is the contour-branch matrix of the electric circuit, elements of which $g_{i j}$ are numbers $1,-1$, or 0 depending on whether the $\mathrm{j}$-th branch enters the $\mathrm{i}$-th circuit in the same direction, in the opposite direction, or is not connected with it at all.

In accordance with (3) and (4), the following expression for a grid appears; it does not contain transforming elements:

$$
I_{B}=G_{E E}^{T}\left(G_{E E} Z_{B}^{E} \Gamma_{E E}^{T}\right)^{-1} G_{E E} E_{B}
$$

From matrix $I_{\mathrm{B}}$ and complex conjugate matrix $\widetilde{I}_{\mathrm{B}}$, the power matrix can be obtained: 


$$
S_{B}=I_{\mathrm{B}} \cdot \operatorname{diag}\left(Z_{B}^{E}\right) * \widetilde{I}_{\mathrm{B}}
$$

where diag is the function forming a matrix column of diagonal elements from the diagonal elements of the matrix $Z_{B}^{E}$, which is an argument, and the operation (.*) corresponds to the elementwise multiplication of matrix elements.

Next, a parallel grid must be considered; an equivalent circuit of substitution of parallel grids is shown in Fig. 2. It operates a harmonic emf $\mathrm{E}$ with internal resistance $r_{0}$, load resistances $Z_{1}, Z_{2}, \ldots, Z_{n}$ connected by resistive wires $z_{1}, z_{2}, \ldots, z_{n}$.

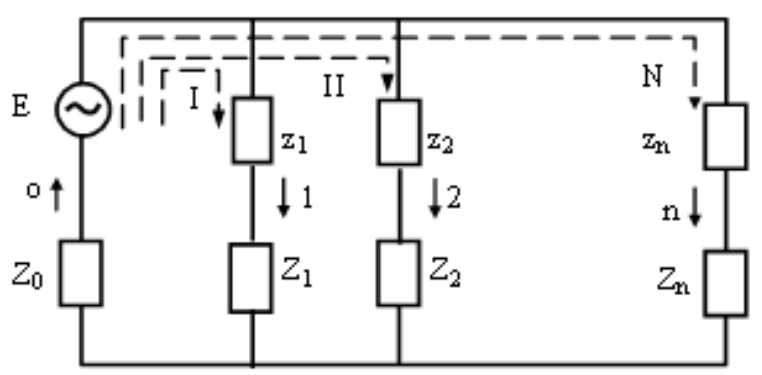

Fig. 2. The equivalent circuit for substitution of parallel grids.

In accordance with the accepted numbering of branches and contours and positive directions for them, the following expressions for the contour-branch matrix, resistance matrix, and emf matrix appears:

$$
\begin{aligned}
\Gamma_{E E<n, n+1>} & =\left(\begin{array}{c:cccc}
1 & 1 & 0 & \ldots & 0 \\
1 & 0 & 1 & \ldots & 0 \\
\ldots & \ldots & \ldots & \ldots & \ldots \\
1 & 0 & 0 & \ldots & 1
\end{array}\right) E_{B<n+1,1>}=\left(\begin{array}{c}
E \\
0 \\
\ldots \\
0
\end{array}\right)_{<n+1,1>} \\
Z_{B<n+1, n+1>}^{E} & =\left(\begin{array}{c:ccccc}
z_{0} & 0 & 0 & \ldots & 0 \\
\hdashline 0 & Z_{1}+z_{1} & 0 & \ldots & 0 \\
0 & 0 & Z_{2}+z_{2} & \ldots & 0 \\
\ldots & \ldots & \ldots & \ldots & \ldots \\
0 & 0 & 0 & \ldots & Z_{n}+z_{n}
\end{array}\right)
\end{aligned}
$$

Blocking, shown by dashed lines, makes it possible to get the following forms for

$$
\Gamma_{E E<n, n+1>}=\left\lfloor 1_{<n, 1>} \quad H_{<n, n>}\right\rfloor,
$$


where $\mathrm{H}$ is an identity matrix, and

$$
Z_{B}^{E}=\left(\begin{array}{cc}
z_{0<1,1>} & 0_{<1, n>} \\
0_{<n, 1>} & (z+Z)_{<n, n>}
\end{array}\right)
$$

where

$$
Z=\left(\begin{array}{cccc}
z_{1} & 0 & \ldots & 0 \\
0 & z_{2} & \ldots & 0 \\
\ldots & \ldots & \ldots & \ldots \\
0 & 0 & \ldots & z_{n}
\end{array}\right), \quad Z=\left(\begin{array}{cccc}
Z_{1} & 0 & \ldots & 0 \\
0 & Z_{2} & \ldots & 0 \\
\ldots & \ldots & \ldots & \ldots \\
0 & 0 & \ldots & Z_{n}
\end{array}\right)
$$

The resistance matrix of wires $\mathrm{z}$ has active $\mathrm{r}$ and inductive $\mathrm{L}$ components

$$
z=r+j \omega L
$$

The components of the matrix of active resistances can be determined through their sizes, in particular, for the matrix of active resistances it is

$$
r=\frac{4}{\pi}\left(\begin{array}{cccc}
\frac{\rho_{1} l_{1}}{d_{1}^{2}} & 0 & \ldots & 0 \\
0 & \frac{\rho_{2} l_{2}}{d_{2}^{2}} & \ldots & 0 \\
\ldots & \ldots & \ldots & \ldots \\
0 & 0 & \ldots & \frac{\rho_{n} l_{n}}{d_{n}^{2}}
\end{array}\right)=\frac{4}{\pi} \rho l d^{-2}
$$

where

$$
\rho=\left(\begin{array}{cccc}
\rho_{1} & 0 & \ldots & 0 \\
0 & \rho_{2} & \ldots & 0 \\
\ldots & \ldots & \ldots & \ldots \\
0 & 0 & \ldots & \rho_{n}
\end{array}\right), l=\left(\begin{array}{cccc}
l_{1} & 0 & \ldots & 0 \\
0 & l_{2} & \ldots & 0 \\
\ldots & \ldots & \ldots & \ldots \\
0 & 0 & \ldots & l_{n}
\end{array}\right), d=\left(\begin{array}{cccc}
d_{1} & 0 & \ldots & 0 \\
0 & d_{2} & \ldots & 0 \\
\ldots & \ldots & \ldots & \ldots \\
0 & 0 & \ldots & d_{n}
\end{array}\right)
$$

are the matrices of specific resistance of their material, lengths, and diameters.

With account of the block representation of matrices (7) for the current matrix (5), the following expression appears: 


$$
\begin{aligned}
& I_{B}=G_{E E}^{T}\left(\Gamma_{E E} Z_{B}^{E} \Gamma_{E E}^{T}\right)^{-1} G_{E E} E_{B}=
\end{aligned}
$$

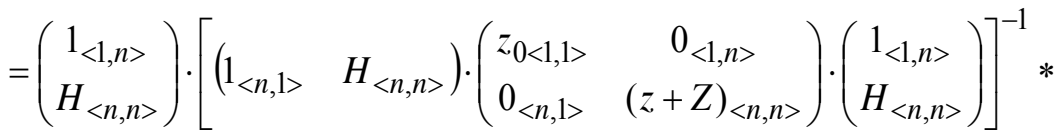

$$
\begin{aligned}
& *\left(1_{<n, 1>} \quad H_{<n, n>}\right) \cdot\left(\begin{array}{c}
E \\
0 \\
\ldots \\
0
\end{array}\right)_{<n+1,1>}=\left(\begin{array}{c}
1_{<1, n>} \\
H_{<n, n>}
\end{array}\right) \cdot Z_{\Sigma}^{-1}\left(1_{<n, 1>} \quad H_{<n, n>}\right) \cdot\left(\begin{array}{c}
E \\
\cdots \\
0 \\
\ldots \\
0
\end{array}\right)_{<n+1,1>}
\end{aligned}
$$

Where

$$
\begin{gathered}
E_{K}=Z_{K}^{E} I_{K}+Z_{K}^{E M} F_{K} \\
0=Z_{K}^{M E} I_{K}+Z_{K}^{M} F_{K} \\
Z_{\Sigma}=\left[\begin{array}{cccc}
\left(z_{0}+z_{1}+Z_{1}\right) & z_{0} & \ldots & z_{0} \\
z_{0} & \left(z_{0}+z_{2}+Z_{2}\right) & \ldots & z_{0} \\
\ldots & \ldots & \ldots & \ldots \\
z_{0} & z_{0} & \ldots & \left(z_{0}+z_{n}+Z_{n}\right)
\end{array}\right]
\end{gathered}
$$

Notations for the conductivity matrix must be introduced:

$$
Z_{\Sigma}^{-1}=Y=\left(\begin{array}{cccc}
y_{11} & y_{12} & \ldots & y_{1 n} \\
y_{21} & y_{22} & \ldots & y_{2 n} \\
\ldots & \ldots & \ldots & \ldots \\
y_{n 1} & y_{n 2} & \ldots & y_{n n}
\end{array}\right)
$$

Taking this into account, we can find from (14)

$$
I_{B}=\left(\begin{array}{c}
1_{<1, n>Y_{<n, n>}} \\
H_{<n, n>}
\end{array}\right) \cdot Y_{\Sigma}\left[\begin{array}{ll}
1_{<n, 1>} & H_{<n, n>}
\end{array}\right] \cdot\left(\begin{array}{c}
E \\
\cdots \\
\ldots \\
\ldots \\
0
\end{array}\right)_{<n+1,1>}=Y_{B} \cdot\left(\begin{array}{c}
E \\
\cdots \\
\ldots \\
0
\end{array}\right)_{<n+1,1>}
$$

where 


$$
\begin{aligned}
& Y_{B}=\left(\begin{array}{c}
1_{<1, n>Y_{<n, n>}} \\
H_{<n, n>}
\end{array}\right) \cdot Y \cdot\left(1_{<n, 1>} \quad H_{<n, n>}\right) \cdot\left(\begin{array}{c}
E \\
\cdots \\
0 \\
\ldots \\
0
\end{array}\right)_{<n+1,1>}= \\
& =\left[\begin{array}{ccccc}
\left(\sum_{j=1}^{n} \sum_{i=1}^{n} y_{i j}\right) & \left(\sum_{j=1}^{n} y_{j, 1}\right) & \left(\sum_{j=1}^{n} y_{j, 2}\right) & \ldots & \left(\sum_{j=1}^{n} y_{j, n}\right) \\
\left(\sum_{i=1}^{n} y_{i, 1}\right) & y_{1,1} & y_{1,2} & \ldots & y_{1, n} \\
\left(\sum_{i=1}^{n} y_{i, 2}\right) & y_{2,1} & y_{2,2} & \ldots & y_{2, n} \\
\left(\sum_{i=1}^{n} y_{i, n}\right. & \ldots & \ldots & \ldots & \ldots \\
y_{n, 1} & y_{n, 2} & \ldots & y_{n, n}
\end{array}\right] .
\end{aligned}
$$

The given matrix relations will be used to form the patterns of the ongoing processes occurring in the chain under consideration, as well as to solve several analytical problems.

\section{Discussion}

Power matrix (6), determined based on the matrix calculated using (17), gives complete information about the active and reactive components of all branches of the circuit. This particularly makes it possible to solve problems of grid optimization according to criteria related to minimizing the loss of reactive power, and also generate patterns for the neural network module and, accordingly, control signals for correction devices for typical network modes. The presented matrix model of the network under consideration takes into account all parameters of conducting lines and the operation of consumers in almost real-time, which provides a higher performance of the control system based on network monitoring in comparison with the use of other topological methods in the model.

To implement the above-calculated dependencies, it is advisable to use the MATLAB environment, focused on the implementation of matrix analysis. In it, in particular, various modifications of the summation function sum of matrix Y can be used to calculate the block components of matrix (18), i.e.

$$
Y_{B}=\left[\begin{array}{ccccc}
\operatorname{sum}(\operatorname{sum}(\mathrm{Y})) & \operatorname{sum}(Y(1,:), 1) & \operatorname{sum}(Y(1,:), 2) & \ldots & \operatorname{sum}(Y(1,:), n) \\
\operatorname{sum}(Y(:, 1), 1) & Y(1,1) & Y(1,2) & \ldots & Y(1, n) \\
\operatorname{sum}(Y(:, 2), 1) & Y(2,1) & Y(2,3) & \ldots & Y(2, n) \\
\ldots & \ldots & \ldots & \ldots & \ldots \\
\operatorname{sum}(Y(:, n), 1) & Y(n, 1) & Y(n, 2) & \ldots & Y(n, n)
\end{array}\right]
$$

It should be noted that as a correction execution device it is recommended to use a highspeed compensator which makes it possible to permanently monitor the flow of reactive power in the node or line under consideration and which has high specific technical and economical indicators. Currently, the SVCs that are built on the principle of the indirect 
compensation system, like static reactive power compensator for indirect reactive power compensation system shown on Fig. 3, are the most widely used. In such an SVC, a thyristor-controlled inductor $\mathrm{L}$ is connected in parallel with a high-capacity bank C [9].

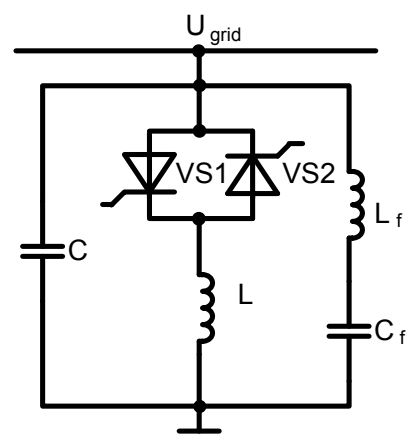

Fig. 3. Static reactive power compensator for an indirect reactive power compensation system.

When the operator changes the control angle of thyristors VS1 - VS2 throughout the whole range of throttle regulation, choke inductive conductivity varies from a maximum value to zero, and the equivalent conductance of an SVC varies from a minimum to a maximum value. The disadvantages of such an SVC are high weight and size parameters and the specific losses of elements of the device (losses in the structure of the device per unit of power) : of the capacitor bank, chokes, and thyristor regulators.

The most acceptable option of an SVC with the best specific indices and similar dynamic characteristics is a static compensator based on magneto-valve elements (MVEs), the single-phase design of which is shown in Fig. 4.

A feature of the proposed schematic variant of the SVC is the regulation of the reactive power of the static compensator according to the principle of a variable structure depending on the state of the thyristor phase-controlled key VS. During the half-period of the supply mains voltage, the compensator generally works in two modes. The first mode corresponds to the closed state of the symmetric thyristor VS, while the device generates maximum reactive power in the electrical grid. The second corresponds to the open state of the symmetric thyristor VS, in which the windings of the middle w1 and extreme w2 rods, with the corresponding mutually inductive coupling between them, turn out to be turned in the opposite direction. As a result, their equivalent inductive resistance is reduced, causing a significant inductive current to the flow. The capacitor bank $\mathrm{C}$ is connected to the grid through the only inductive coupling via the winding of the terminal rod w3. Depending on the ratio of the parameters of the windings and the magnetic circuit in the second mode, the reactive power of the SVC can amount to zero. By changing the opening angle of the thyristors, the effective value of the SVC reactive power can be changed from maximum to zero values within one period of the mains voltage. The symmetric thyristor is controlled by the phase-pulse method with natural switching. 


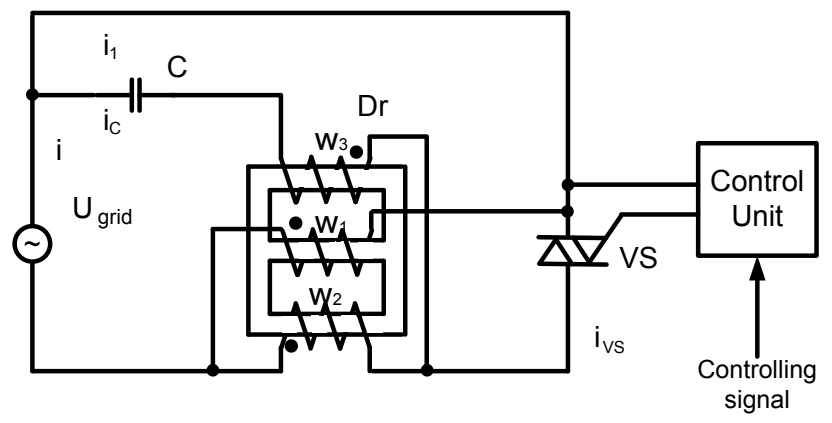

Fig. 4. Static reactive power compensator based on magneto-valve elements.

For the amplitude of the first harmonic of the current SVC, the ratio for reactive power power offset can be obtained; it is a function of the control angle of thyristors $\alpha$ [10]:

$$
\begin{aligned}
& Q(\alpha)=-\frac{U_{m} I_{\mathrm{I} m \mathrm{E}}}{2 \pi}[\pi-(\beta-\alpha)+\sin (\beta-\alpha)] \sin \varphi_{(1)}+ \\
& +\frac{U_{m} I_{\operatorname{II} m E}}{2 \pi}[(\beta-\alpha)-\sin (\beta-\alpha)] \sin \varphi_{(1)},
\end{aligned}
$$

where $\varphi(1)$ is the phase angle of the first harmonic of the current relative to the mains voltage;

$\beta$ is the thyristor conductivity angle.

The adjustment characteristic of the SVC based on the MVE is presented in Fig. 5.

As the analysis of electrical parameters shows, the proposed version of the compensator has high specific indices:

$$
\mathrm{Q}_{\mathrm{dr}}=0,5 \mathrm{Q}_{\mathrm{svC}}, \mathrm{Q}_{\mathrm{sv}}=0,5 \mathrm{Q}_{\mathrm{svC}}, \mathrm{I}_{\mathrm{vS}}=0,3 \mathrm{I}_{\mathrm{nom}},
$$

$\Delta \mathrm{P}=10 \mathrm{Wt} / \mathrm{kVAr}$ are the specific power losses in the SVC

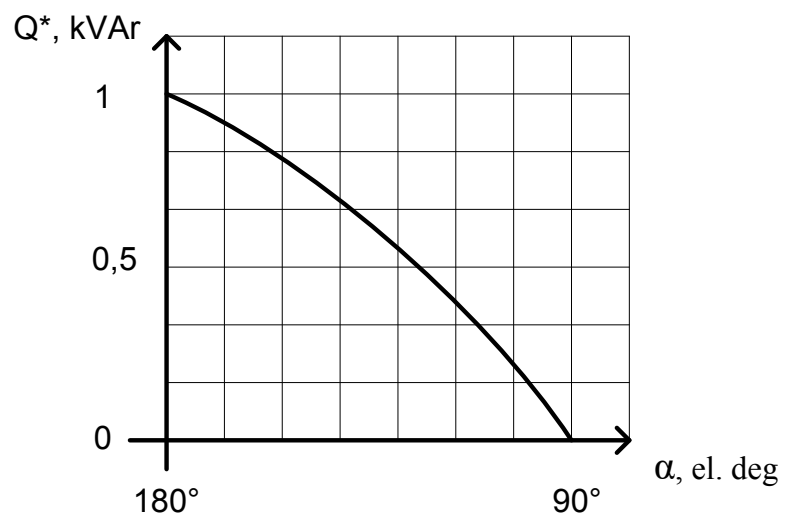

Fig. 5. Adjustment characteristic of SVC based on magneto-valve elements.

\section{Conclusion}

Application of matrix analysis in control signal generation system with correction devices allows to prevent extreme situations and to solve problems of grid optimization according 
to criteria related to minimization of reactive power losses to select and install reactive power compensation devices and control them. Application of a SVC as a correction device based on magneto-valve elements additionally increases efficiency of reactive power compensation in grids with sharply variable character of power consumption.

\section{References}

1. V. YA. Ushakov Sovremennyye problemy elektroenergetiki: uchebnoye posobiye, Tomskiy politekhnicheskiy universitet, (Izd-vo Tomskogo politekhnicheskogo universiteta, Modern problems of the electric power industry: textbook, Tomsk. 2013).

2. A. F. Butkevich, I. A. Kostyrya Ispol'zovaniye FACTS dlya povysheniya propusknoy sposobnosti elektricheskikh setey, Pratsi instytutu elektrodynamiky Natsional'noyi akademiyi nauk ukrayiny, 44, 5-12 (2016).

3. J. Barati, A. Saeedian, S. Mortzavi Damping power systems oscillations improvement by FACTS devices: a comparison between SSSC and STATCOM, World academy of science. Engineering and technology, 4, 179 - 187 (2010).

4. S. Bindeshwar, K. Verma and others Introduction to FACTS controllers. A critical review, International journal of reviews in computing, 8, 17 - 34 (2011).

5. V. V. Yudin Calculation of linear electromagnetic circuits by the method of combined matrices, Electricity, 7, 63 - 67 (1987).

6. V. Z. Manusov, E. V. Biryukov Kratkosrochnoye prognozirovaniye elektricheskoy nagruzki na osnove nechetkoy neyronnoy seti i yeye sravneniye s drugimi metodami, Izvestiya tomskogo politekhnicheskogo universiteta, 309 (6), 153-157 (2006)

7. A.I. Chivenkov, N.N. Vikhorev, I.M. Trofimov, A. Gedifa Physical model of SMART GRID, Transactions of NNSTU n.a. R.E. ALEKSEEV, 1(116), 83 - 89 (2016).

8. V. V. Yudin The branch form of the equations of the electromagnetic circuit Bulletin of the Upper Volga branch of the Academy of Technological Sciences of the Russian Federation. (Transactions Rybinsk. 2003).

9. U. M. In'kov, V. S. Klimash, D. P. Svetlakov Kompensatory neaktivnoy energii so stabilizatsiyey napryazheniya transformatornykh podstantsiy, Elektrotekhnika, 7, 34 37 (2007).

10. A. B. Manin, N. V. Chizhikova, O. A. Moskaleva Bystrodeystvuyusheye simmetriruyushcheye ustroystvo, Novyye tekhnologii v promyshlennosti i sel'skom khozyaystve, materialy 1-y vserossiyskoy zaochnoy nauchnoprakticheskoy konferentsii, OOO «Mezhdunarodnyy tsentr tekhnologiy», 39 -44 (2012). 